\title{
Efeitos do ácido hialurônico no tratamento de feridas de pacientes com pé
}

\section{diabético}

\author{
Effects of hyaluronic acid in the treatment of wounds in patients with diabetic foot \\ Efectos del ácido hialurónico en el tratamiento de heridas en pacientes con pie diabético
}

Recebido: 30/04/2021 | Revisado: 09/05/2021 | Aceito: 12/05/2021 | Publicado: 29/05/2021

\author{
Eurides Regina Costa Soares Rocha \\ ORCID: https://orcid.org/0000-0002-8301-4760 \\ Centro Universitário Santo Agostinho, Brasil \\ E-mail: euridescalcados@gmail.com \\ Francisco Adalberto do Nascimento Paz \\ ORCID: https://orcid.org/0000-0001-6697-1705 \\ Centro Universitário Santo Agostinho, Brasil \\ E-mail: pazadalberto19@ hotmail.com
}

\begin{abstract}
Resumo
Objetivou-se nesse estudo avaliar com base nas evidências científicas a ação do ácido hialurônico no tratamento de feridas de pacientes com pé diabético. Foi realizado um estudo de revisão integrativa da literatura que utilizou como base de dados as plataformas: Biblioteca Virtual em Saúde (BVS), Literatura Latino-Americana e do Caribe em Ciências da Saúde (LILACS), Base de Dados de Enfermagem (BDENF), Sistema Online de Busca e Análise de Literatura Médica (MEDLINE). Foram utilizados os descritores: "Ácido hialurônico", "Tratamento", "Cicatrização de feridas". No total foram obtidos 685 artigos, que após serem submetidos aos critérios de inclusão e exclusão, restaram 144 para avaliar os resumos. Após análise dos resumos, 10 artigos foram selecionados no estudo. Os resultados do estudo evidenciaram que o ácido hialurônico se mostrou bastante eficaz na maioria dos artigos selecionados, demonstrando rapidez na cicatrização de feridas, aumento da granulação do tecido e revitalização da ferida, melhora no suprimento de sangue até o local da ferida, produção de queratinócitos, redução de alguns sinais clínicos como: secreção, purulência, odor e nível de exsudato, demonstrando boa capacidade de absorção de água e taxa de cura completa. Conclui-se que a utilização do HA em feridas diabéticas configura uma importante ferramenta para minimizar internações relacionadas a condição de diabetes, reduzindo altos índices de amputação de membros inferiores, sobretudo os estudos não demonstram contraindicações severas e nem efeitos maléficos que condissessem repercussões negativas ao seu uso, favorecendo a cicatrização e cura em curto período de tempo.
\end{abstract}

Palavras-chave: Ácido Hialurônico; Pé Diabético; Cicatrização.

\begin{abstract}
The objective of this study was to evaluate, based on scientific evidence, the action of hyaluronic acid in the treatment of wounds in patients with diabetic foot. An integrative literature review study was carried out using the following platforms: Virtual Health Library (VHL), Latin American and Caribbean Literature in Health Sciences (LILACS), Nursing Database (BDENF), as a database. Online Medical Literature Search and Analysis System (MEDLINE). The descriptors were used: "Hyaluronic acid", "Treatment", "Wound healing". In total, 685 articles were obtained, which after being submitted to the inclusion and exclusion criteria, 144 remained to evaluate the abstracts. After analyzing the abstracts, 10 articles were selected in the study. The results of the study showed that hyaluronic acid was shown to be quite effective in most of the selected articles, demonstrating rapid wound healing, increased tissue granulation and wound revitalization, improved blood supply to the wound site, keratinocyte production, reduction of some clinical signs such as: secretion, purulence, odor and exudate level, showing good water absorption capacity and complete cure rate. It is concluded that the use of $\mathrm{AH}$ in diabetic wounds is an important tool to minimize hospitalizations related to the condition of diabetes, reducing high rates of amputation of lower limbs, above all studies do not demonstrate severe contraindications or harmful effects that would lead to negative repercussions for its use, favoring healing and healing in a short period of time.
\end{abstract}

Keywords: Hyaluronic acid; Diabetic foot; Healing.

\section{Resumen}

El objetivo de este estudio fue evaluar, con base en la evidencia científica, la acción del ácido hialurónico en el tratamiento de heridas en pacientes con pie diabético. Se realizó un estudio de revisión integradora de la literatura utilizando las siguientes plataformas: Biblioteca Virtual en Salud (BVS), Literatura Latinoamericana y del Caribe en Ciencias de la Salud (LILACS), Base de Datos de Enfermería (BDENF), como base de datos. Sistema de Búsqueda y Análisis de Literatura Médica en Línea (MEDLINE). Se utilizaron los descriptores: "Ácido hialurónico", 
"Tratamiento", "Cicatrización de heridas". En total se obtuvieron 685 artículos, que luego de ser sometidos a los criterios de inclusión y exclusión quedaron 144 para evaluar los resúmenes. Después de analizar los resúmenes, se seleccionaron 10 artículos en el estudio. Los resultados del estudio mostraron que el ácido hialurónico demostró ser bastante eficaz en la mayoría de los artículos seleccionados, demostrando una rápida cicatrización de heridas, aumento de la granulación del tejido y revitalización de la herida, mejor suministro de sangre al sitio de la herida, producción de queratinocitos, reducción de algunos signos clínicos como como: secreción, purulencia, olor y nivel de exudado, mostrando buena capacidad de absorción de agua y tasa de curación completa. Se concluye que el uso de HA en heridas diabéticas constituye una herramienta importante para minimizar las hospitalizaciones relacionadas con la condición de diabetes, reduciendo altas tasas de amputación de miembros inferiores, sobre todo estudios no demuestran contraindicaciones severas o efectos nocivos que conduzcan a repercusiones negativas. a su uso, favoreciendo la cicatrización y cicatrización en un corto período de tiempo.

Palabras clave: Ácido hialurónico; Pie diabético; Cicatrización.

\section{Introdução}

A pele configura o maior órgão do corpo humano e tem como função principal separar as estruturas internas do meio externo, sendo formada por três diferentes camadas: epiderme, derme e hipoderme; a camada que é vista externamente é a derme, age protegendo o corpo de agentes externos e possui espessura 75 a 150mm, as células que compõem essa camada são queratinócitos, melanócitos, células de Merkel e de Langerhans. A segunda camada é a derme, que fica localizada entre a epiderme e a hipoderme, formada por tecido conjuntivo denso e irregular, rico em fibras colágeno e elastina, sua espessura varia entre $0,6 \mathrm{~mm}$ a $3 \mathrm{~mm}$. A última camada hipoderme que é constituída por adipócitos, tem como função principal, reserva energética e proteção contra possíveis choques (Bernardo et al. 2019).

O pé diabético representa uma das complicações mais frequentes do paciente com Diabetes Mellitus, é evidenciada por lesões na região dos pés em resultado de alterações vasculares periféricas e/ou neurológicas peculiares do DM, composto pela tríade: neuropatia, doença vascular periférica e infecção. Em que se não tratada de forma precoce, pode evoluir para gangrena e amputação do membro (Santos ICRV, 2011 como citado em Gois, 2020, p. 2).

O aparecimento de ulcera plantar no pé (UPP), se dá por um processo crônico que cria condições para desenvolver esse tipo de lesão nessa região, os fatores que colaboram para tal são: neuropatia periférica, que leva a perda de sensibilidade protetora nos pés; doença arterial periférica e alterações biomecânicas provocadas pela destruição osteoarticular; a prevenção e o tratamento de UPP constitui uma das principais preocupações pois infecções acometem 58\% dos pacientes que apresentam uma nova UPP, e em manifesto disso 5\% destes pacientes sofrerão uma amputação maior no prazo de até 1 ano, logo é notável que pacientes diabéticos que desenvolvem lesões nos pés estão sujeitos à alta incidência de morte prematura diretamente relacionada ao elevado risco de sofrer uma amputação maior em pelo menos um dos membros inferiores no decorrer da vida (Ferreira, 2020).

Estudos demonstram cada vez mais a eficácia e segurança da utilização do ácido hialurônico para aceleração da cicatrização tecidual, fibrose, melhora significativa da angiogênese e efeitos anti-inflamatórios no tratamento de feridas, o que indica que a implementação deste produto para o tratamento de feridas sobretudo em pacientes com pé diabético, representa um acentuado avanço uma vez que a grande maioria dos tratamentos é realizado através de antibióticos, porém com avançar dos anos os microrganismos tem se mostrado progressivamente mais resistentes, tornando a terapia com fitoterápicos mais necessários (Pádua, 2020). 
Segundo André \& Rodrigues (2011) a cicatrização de feridas constitui um processo complexo e coordenado, envolvendo a interação entre células e vários sistemas mensageiros. Este processo pode dividir-se em três fases: inflamatória, proliferativa e de remodelação. A primeira corresponde a fase onde acontece fenômenos vasculares, proliferativa e de remodelação, hemóstase e coagulação, e outra por mecanismos predominantemente celulares. A fase proliferativa é vista um razoável predomínio de mecanismos celulares que propiciam a produção de uma nova barreira permeável (reepitelização), neovasos (angiogénese) e reestruturação da integridade da derme (fibroplasia). E a última fase representa a deposição de novos elementos da matriz extracelular e na sua alteração no decorrer do tempo, acontece ao longo de todo processo de cicatrização à medida que o coágulo de fibrina é trocado por tecido de granulação.

O Ácido Hialurônico (AH) é um componente da matriz extracelular que favorece a cicatrização e controla a exposição excessiva de colágeno nas cicatrizes. Sua ação engloba a melhora da atividade dos neutrófilos, aumento da motilidade celular, deposição de colágeno, estimulação da anfigênese e a proliferação celular (Araújo et al. 2017).

A aplicação do Ácido Hialurônico no tratamento de feridas, assim como visto em outros estudos age de forma positiva na cicatrização, e atua positivamente com outros agentes de coberturas, sem qualquer rejeição, sendo sua eficácia bastante significativa (Dalmedico et.al. 2016).

Devido ao crescimento do uso de ácido hialurônico no tratamento de feridas, e especificamente no pé diabético foi observado a suma importância de se elaborar uma pesquisa com essa temática, em que proporcionará conhecimentos embasados em dados científicos relevantes aos profissionais de saúde assim como os acadêmicos de enfermagem, enfatizando os benefícios desse ácido e estimulando a continuação de novos estudos e pesquisas nesse âmbito. Com vista a alcançar o maior número de leitores, a pesquisa pretende-se ser publicada em periódicos e em congressos nacionais e internacionais.

Diante desse contexto, a pesquisa tem como questão norteadora: Quais os efeitos do ácido hialurônico no tratamento de feridas de paciente com pé diabético? Indicando como objetivo geral descrever com base nas evidencias científicas a ação do ácido hialurônico no tratamento de feridas de pacientes com pé diabético.

\section{Metodologia}

O presente estudo é uma revisão bibliográfica de literatura pelo método revisão integrativa, que relata sobre os efeitos do ácido hialurônico no tratamento de feridas de pacientes com pé diabético. Sendo uma ferramenta de investigação que permite à procura, a avaliação crítica e a síntese das evidências disponíveis sobre o tema investigado, em que o produto final é o estado do conhecimento, a implementação de intervenções efetivas na prestação de cuidados e na redução de custos. Além disso, permite a identificação de fragilidades, que poderão conduzir ao desenvolvimento de futuras investigações (Sousa, Marques-Vieira, Severino \& Antunes 2017).

A revisão configura-se, portanto, a união de achados de estudos desenvolvidos mediante diferentes metodologias, permitindo aos revisores sintetizar resultados sem ferir a filiação epistemológica dos estudos empíricos incluídos. Para que esse processo se concretize de maneira lógica, isenta de desatinos epistemológicos, a revisão requer que os revisores procedam à análise e à síntese dos dados primários de forma sistemática e rigorosa (soares et al. 2014).

Tal instrumento de estudo requer um padrão de excelência quanto ao rigor metodológico para que seu produto possa trazer contribuições significativas para a ciência e para a prática clínica. A preservação deste padrão requer o uso de métodos que garantam a análise precisa, objetiva e completa do tema revisado; o suporte teórico para analisar resultados, métodos, sujeitos e variáveis dos estudos primários; a provisão de todas as informações contidas nos estudos revisados e não apenas os principais resultados, de modo a informar o leitor sem o sobrecarregar com informações desnecessárias (soares et al. 2014). 
A revisão integrativa permite que o leitor reconheça os principais autores que mais investigam determinado assunto, separar o achado científico de opiniões e ideias, além de descrever o conhecimento no seu estado atual, promovendo impacto sobre a prática clínica. Este método de pesquisa proporciona aos profissionais de saúde dados relevantes de um determinado assunto, em diferentes lugares e momentos, mantendo-os atualizados e facilitando as mudanças na prática clínica como consequência da pesquisa. Dessa forma, acreditamos que a revisão integrativa é uma ferramenta importante no processo de comunicação dos resultados de pesquisas, facilitando a utilização desses na prática clínica, uma vez que proporciona uma síntese do conhecimento já produzido e fornece subsídios para a melhoria da assistência à saúde (Mendes, Silveira \& Galvão 2008).

Fluxograma 1. Fases distintas da revisão integrativa.

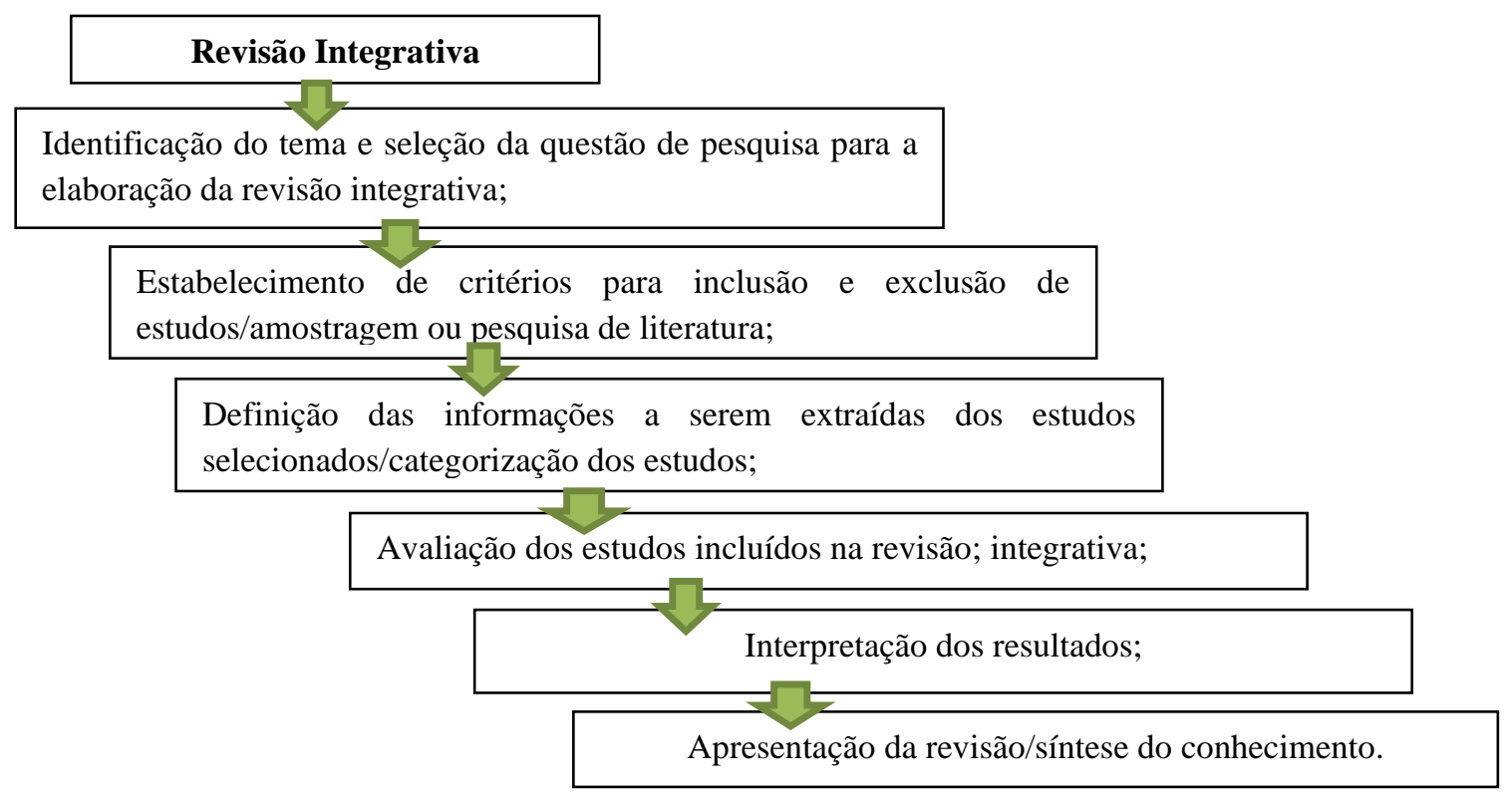

Fonte: Mendes, Silveira \& Galvão (2008).

A revisão integrativa é um tipo de pesquisa que fornece informações mais amplas de maneira sistemática, ordenada e abrangente, sobre um assunto ou tema, com finalidade de sintetizar resultados obtidos em pesquisa sobre temas ou questões. A definição das informações a serem extraídas dos estudos selecionados por categorização; avaliação dos estudos incluídos; interpretação dos resultados; e apresentação da revisão/síntese do conhecimento (Ercole, Melo \& Alcoforado 2014).

Foram utilizados para busca de dados as fontes das seguintes bases de dados: Biblioteca Virtual em Saúde (BVS), Literatura Latino-Americana e do Caribe em Ciências da Saúde (LILACS), Base de Dados de Enfermagem (BDENF), Sistema Online de Busca e Análise de Literatura Médica (MEDLINE). Estabeleceu-se como questão norteadora: "quais os efeitos do ácido hialurônico no tratamento de feridas de pacientes com pé diabético?”, e para tal foi utilizado a estratégia "PICo", (P População/Problema: pacientes com pé diabético; I interesse: efeitos do ácido hialurônico; Co contexto: tratamento de feridas. Para seleção dos artigos foram aplicados os descritores: “Ácido hialurônico", "Tratamento", “Cicatrização de feridas”, conectados ao operador booleano "AND".

Os critérios de inclusão estabelecidos foram: artigos indexados em texto completo, nas línguas portuguesa, inglesa e espanhola, que tiveram como assunto principal “Ácido hialurônico”, “Cicatrização”, "Pé Diabético”, que foram publicados no período entre (2016 a 2021). Os critérios de exclusão estabelecidos na seleção foram artigos incompletos, artigos duplicados e em outras línguas. 
No início da pesquisa obteve-se 685 artigos, após a realização da leitura dos títulos dos artigos, foi visto que alguns se repetiam nas diferentes bases de dados e ou não se encaixavam nos critérios do estudo. Foram escolhidos 144 artigos para avaliação dos resumos, e excluídos os que não se relacionavam a temática abordada. Com a leitura dos resumos, 10 artigos foram selecionados para categorização, como mostra a Figura 1.

Figura 1. Mecanismo de busca para apuramento dos artigos. Teresina, 2021.

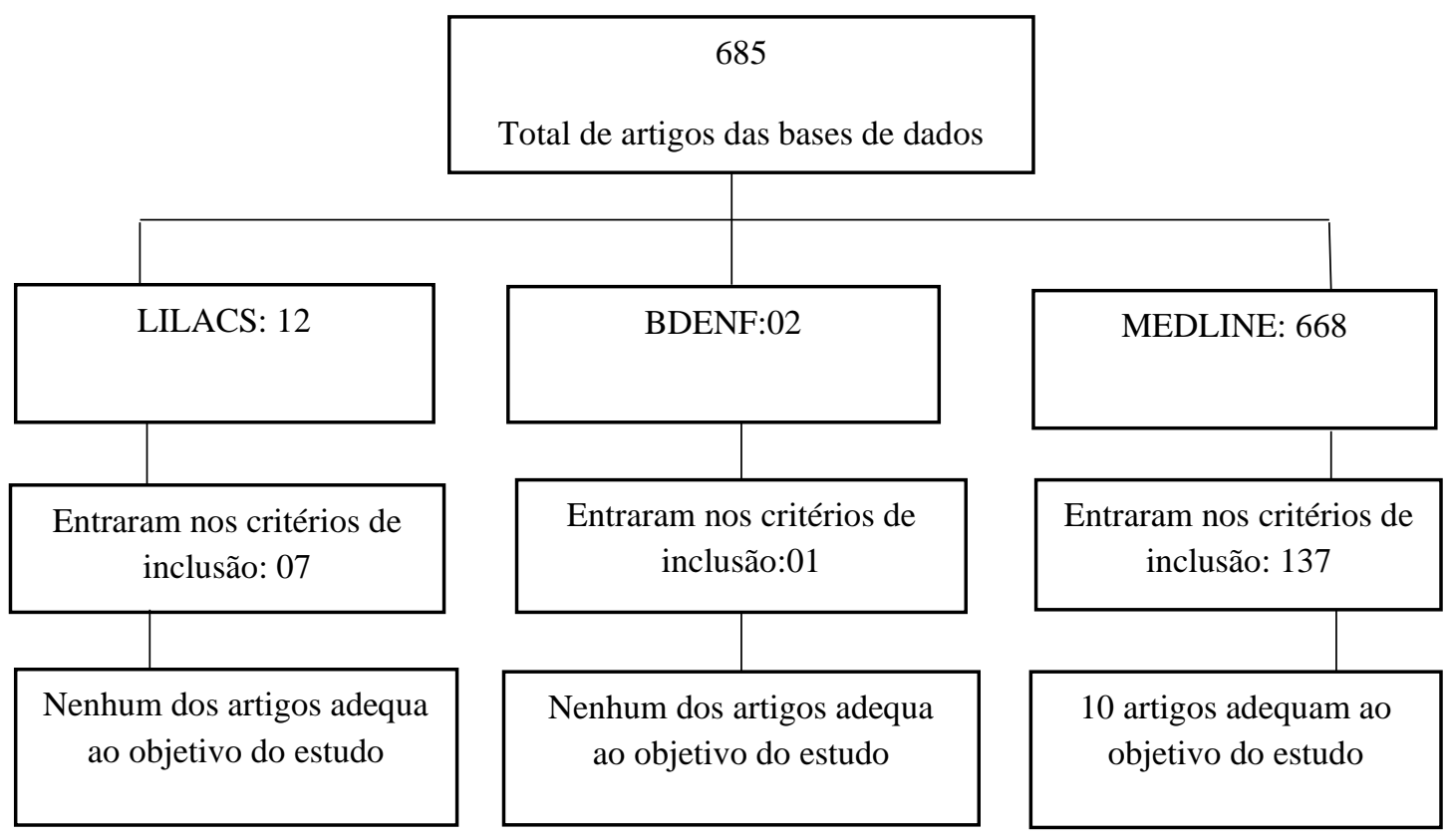

Fonte: Direta de pesquisa. Teresina (2021).

O estudo apresentado de revisão integrativa garante os aspectos éticos e legais, assegurando com veridicidade a autoria dos artigos explorados, tanto autores citados no decorrer do texto do presente estudo como autores citados nas referências, submetendo as normas da Associação Brasileira de Normas Técnicas (ABNT) e do manual de normatização e estrutura do trabalho de conclusão de curso do Centro Universitário Santo Agostinho (UNIFSA).

\section{Resultados}

Com base na leitura e análise do material encontrado, foi possível organizar e agrupar informações significativas dos artigos e em seguida foram distribuídos em tabelas e quadros para facilitar a compreensão e entendimento. A Tabela 1 Expõe a distribuição das produções científicas, diante do ano de publicação, Idioma e Periódico de publicação.

Tabela 1: Distribuição dos artigos conforme o período de publicação, idioma e periódico de publicação. Teresina, 2021.

\begin{tabular}{|l|l|l|}
\hline ANO DE PUBLICAÇÃO & $\mathbf{N}^{\circ}$ & $\%$ \\
\hline Dois mil e dezesseis & Dois & Vinte por cento \\
\hline Dois mil e dezessete & Três & Trinta por cento \\
\hline Dois mil e dezenove & Dois & Vinte por cento \\
\hline
\end{tabular}


Research, Society and Development, v. 10, n. 6, e24610615623, 2021

(CC BY 4.0) | ISSN 2525-3409 | DOI: http://dx.doi.org/10.33448/rsd-v10i6.15623

\begin{tabular}{|c|c|c|}
\hline Dois mil e vinte & Três & Trinta por cento \\
\hline IDIOMA & $\mathbf{N}^{\circ}$ & $\%$ \\
\hline Inglês & Dez & Cem por cento \\
\hline PERIÓDICO DE PUBLICAÇÃO & $\mathbf{N}^{\circ}$ & $\%$ \\
\hline Med Oral Patol Oral Cir Bucal & Um & Dez por cento \\
\hline J Wound Care & Um & Dez por cento $\%$ \\
\hline Eur J Pharm Biopharm & Um & 10 Dez por cento \\
\hline Am J Sports Med & Um & Dez por cento $\%$ \\
\hline J Invest Dermatol & Um & Dez por cento \% \\
\hline Pharmacol Rep & Um & Dez por cento $\%$ \\
\hline Wound Repair Regen & Um & Dez por cento \% \\
\hline Int Wound $\mathbf{J}$ & Um & Dez por cento \\
\hline Int J Mol Sci & Um & Dez por cento \\
\hline Res Vet Sci & Um & Dez por cento \\
\hline
\end{tabular}

Fonte: Pesquisa direta de base de dados. Teresina (2021).

De acordo com o detalhamento e organização das informações inerentes aos dados bibliográficos, foi possível observar que os anos que mais se obteve publicações foi de 2017 e 2020 com um total de 30\%, em seguida 2016 e 2019 com $20 \%$.

Quanto a linguagem utilizada, a língua inglesa apresentou uma alta predominância com cerca de $100 \%$ de todos os artigos publicados. Já em relação aos periódicos publicados, a revista Med Oral Patol Oral Cir Bucal apontou 10\% nos números de publicação, assim como as revistas J Wound Care, Eur J Pharm Biopharm, Am J Sports Med, J Invest Dermatol, Pharmacol Rep, Wound Repair Regen, Int Wound J, Int J Mol Sci, Res Vet Sci.

O Quadro 1 apresenta a distribuição dos dados relativos aos trabalhos científicos, de acordo com (título, ano, autores e resultados relevantes). Para uma melhor interpretação dos resultados encontrados, os artigos levaram uma enumeração de 1 a 10 visando uma melhor visualização para identificar as etapas. 
Quadro 1. Distribuição dos estudos conforme o título, ano, autores e resultados relevantes. Teresina, 2021.

\begin{tabular}{|c|c|c|c|c|}
\hline $\mathbf{N}^{\circ}$ & Título & Ano & Autores & Resultados Relevantes \\
\hline 01 & $\begin{array}{l}\text { Curativo de ácido hialurônico } \\
\text { (Healoderm) no tratamento de } \\
\text { úlcera de pé diabético: um } \\
\text { estudo prospectivo, } \\
\text { randomizado, estudo de } \\
\text { centro único, controlado por } \\
\text { placebo }\end{array}$ & 2016 & $\begin{array}{l}\text { Moses Lee, Seung } \\
\text { Hwan Han, Woo Jin } \\
\text { Choi, Kwang Ho } \\
\text { Chung, Jin Woo Lee }\end{array}$ & $\begin{array}{l}\text { O grupo de estudo apresentou uma taxa de cura } \\
\text { completa em comparação com o controle grupo } \\
\text { [84,6\% (11/13), 41,6\% (5/12), respectivamente, P5 } \\
0,041] \text {. Adicionalmente, velocidade de cicatrização } \\
\text { da úlcera mais rápida e duração média mais curta } \\
\text { para atingir uma úlcera de } 50 \% \text { redução de tamanho } \\
\text { foi observada no grupo de estudo (P50,022 e } 0,004 \text {, } \\
\text { respectivamente). }\end{array}$ \\
\hline 02 & $\begin{array}{l}\text { Os oligossacarídeos de } \\
\text { hialuronano promovem a } \\
\text { cicatrização de feridas } \\
\text { diabéticas, aumentando a } \\
\text { angiogênese. }\end{array}$ & 2016 & $\begin{array}{l}\text { Yi Wang, Guanying } \\
\text { Han, Bin Guo, } \\
\text { Jianhua Huang }\end{array}$ & $\begin{array}{l}\text { O Oligossacarídeos de hialuronano (também } \\
\text { conhecido como ácido hialurônico) (O-HÁ) aumenta } \\
\text { após proliferação, migração e tubo formação de } \\
\text { células endoteliais sob condições de alta glicose e } \\
\text { tóxicos a administração de pomada O-HA promove a } \\
\text { cicatrização de feridas, aumento angiogênese na área } \\
\text { da ferida da pele. }\end{array}$ \\
\hline 03 & $\begin{array}{l}\text { O ácido hialurônico acelera } \\
\text { cura do tendão ao osso após } \\
\text { reparo do rotador manguito }\end{array}$ & 2017 & $\begin{array}{lr}\text { Hirokazu } & \text { Honda, } \\
\text { Masafumi } & \text { Gotoh, } \\
\text { Tomonoshin } & \\
\text { Kanazawa, } & \text { Hiroki } \\
\text { Ohzono, } & \text { Hidehiro } \\
\text { Nakamura, } & \text { Keisuke } \\
\text { Ohta, } \quad \text { Kei-ichiro } & \text { Nakamura, } \quad \text { Kanji } \\
\text { Fukuda, Takeshi } \\
\text { Teramura, }\end{array}$ & $\begin{array}{l}\text { O ácido hialurônico HA acelerou a consolidação do } \\
\text { tendão ao osso no modelo de reparo do manguito } \\
\text { rotador, aumentou a força biomecânica e Aumentar a } \\
\text { formação de condroides e a maturidade do tendão na } \\
\text { interface tendão-osso. Com base nos dados de } \\
\text { experimentos in vitro, HA- MSCs ativadas podem } \\
\text { lançar um papel crucial na aceleração da } \\
\text { consolidação do tendão ao osso. }\end{array}$ \\
\hline 04 & $\begin{array}{l}\text { Hidrogéis esponjosos à base } \\
\text { de ácido hialurônico } \\
\text { carregado com células-tronco } \\
\text { para um sistema integrado } \\
\text { cura de fisiopatologia de } \\
\text { feridas diabéticas }\end{array}$ & 2017 & $\begin{array}{lr}\text { Lucília } & \text { Pereira da } \\
\text { Silva, Tírcia } & \text { Carlos } \\
\text { Santos, } & \text { Daniel } \\
\text { Barreira } & \text { Rodrigues, } \\
\text { Rogério } & \text { Pedro } \\
\text { Pirraco, } & \text { Mariana } \\
\text { Teixeira } & \text { Cerqueira, } \\
\text { Rui Luís } & \text { Reis, Vitor } \\
\text { Manuel } & \text { Correlo, } \\
\text { Alexandra } & \text { Pinto } \\
\text { Marques } & \end{array}$ & $\begin{array}{l}\text { Os hidrogéis esponjosos carregados de células-tronco } \\
\text { representam uma abordagem promissora para } \\
\text { melhorar a cicatrização de feridas diabéticas, } \\
\text { impactando positivamente epitelização e pela } \\
\text { modulação da resposta inflamatória em direção à sua } \\
\text { resolução, que parece ser determinante para uma } \\
\text { neoinervação bem-preparada. }\end{array}$ \\
\hline
\end{tabular}




\begin{tabular}{|c|c|c|c|c|}
\hline 05 & $\begin{array}{l}\text { Cicatrizante de feridas e anti- } \\
\text { inflamatório Efeitos do ácido } \\
\text { hialurônico tópico Injeção na } \\
\text { infecção do sítio cirúrgico } \\
\text { causado por Staphylococcus } \\
\text { aureus }\end{array}$ & 2017 & $\begin{array}{l}\text { Jin Hyung Park, Eon } \\
\text { Ju Park, Hyung Suk } \\
\text { Yi }\end{array}$ & $\begin{array}{l}\text { O grupo ácido hialurônico HA informado um } \\
\text { significativo redução na área da ferida em } \\
\text { comparação com o grupo de controle em patologia } \\
\text { macroscópica (nos dias } 8 \text { pós-procedimento, } 36,54 \% \\
\pm 6,12 \% \text { vs } 50,59 \% \pm 5,50 \%, P<0,001) \text {. O grupo } \\
\text { HA mostrou cicatrização de feridas melhor do que o } \\
\text { grupo controle na análise histológica, incluindo } \\
\text { avaliação de abscesso, infiltração neutrofílica e } \\
\text { necrose }(4,2 \pm 1,2 \text { vs } 11,5 \pm 2,1, P<0,001) \text {. }\end{array}$ \\
\hline 06 & $\begin{array}{l}\text { Ácido hialurônico e prata } \\
\text { metálica tratamento de feridas } \\
\text { crônicas: cura taxa e controle } \\
\text { de carga bacteriana }\end{array}$ & 2019 & $\begin{array}{lr}\text { Luca } & \text { Gazzabin, } \\
\text { Simone } & \text { Serantoni, } \\
\text { Francesco } & \text { Paolo } \\
\text { Palumbo, } & \text { Nicola } \\
\text { Giordan } & \end{array}$ & $\begin{array}{l}\text { Os dados demonstraram boa segurança e } \\
\text { tolerabilidade de o pó de spray tópico sugerindo que } \\
\text { o produto é eficaz, não apenas na redução da área da } \\
\text { ferida, devido à presença de HA, mas em mantendo a } \\
\text { colonização bacteriana sob controle. }\end{array}$ \\
\hline 07 & $\begin{array}{l}\text { Liberação sustentada de } \\
\text { trombomodulina } \\
\text { recombinante de gelatina } \\
\text { reticulada /hidrogéis de ácido } \\
\text { hialurônico potencializam a } \\
\text { cicatrização de feridas em } \\
\text { camundongos diabéticos }\end{array}$ & 2019 & $\begin{array}{l}\text { Yun-Yan Hsu, Kuan- } \\
\text { Lin Liu, Hsun-Hua } \\
\text { Yeh, Hong-Ru Lin, } \\
\text { Hua-Lin Wu, Jui- } \\
\text { Chen Tsai }\end{array}$ & $\begin{array}{l}\text { O rhTM carregado uma vez a cada } 3 \text { dias hidrogel } \\
\text { (com ácido hialurônico) promoveu marcadamente a } \\
\text { cicatrização de feridas e foi superior à solução rhTM, } \\
\text { hidrogel rhTM uma vez ao dia (sem ácido } \\
\text { hialurônico), controles de hidrogel e rhEGF uma vez } \\
\text { a cada } 3 \text { dias grupos de tratamento com hidrogel. }\end{array}$ \\
\hline 08 & $\begin{array}{l}\text { Resultado do tratamento com } \\
\text { ácido hialurônico no pós- } \\
\text { extração cicatrização de } \\
\text { feridas em pacientes } \\
\text { diabetes tipo } 2 \text { mal } \\
\text { controlada: Um estudo } \\
\text { randomizado controlado com } \\
\text { boca dividida }\end{array}$ & 2020 & $\begin{array}{l}\text { Saša Marin, Snježana } \\
\text { Popović-Pejičić, } \\
\text { Bojana Radošević- } \\
\text { Carić, Nataša Trtić, } \\
\text { Zoran Tatić, Srećko } \\
\text { Selaković }\end{array}$ & $\begin{array}{l}\text { O ácido hialurônico colocado no alvéolo pós- } \\
\text { extração em pacientes com diabetes mal controlado } \\
\text { pode melhorar } \\
\text { cicatrização de feridas, principalmente nos primeiros } \\
\text { dias após a aplicação }\end{array}$ \\
\hline 09 & $\begin{array}{l}\text { Ácido hialurônico, mel de } \\
\text { Manuka e gel de Acemannan: } \\
\text { aplicações específicas de } \\
\text { feridas para lesões cutâneas }\end{array}$ & 2020 & $\begin{array}{l}\text { I Iacopetti, A Perazzi, } \\
\text { T Martinello, F } \\
\text { Gemignani, } \\
\text { Patruno }\end{array}$ & $\begin{array}{l}\text { O tratamento com ácido hialurônico HA promoveu } \\
\text { uma progressão fisiológica do processo de } \\
\text { cicatrização em todas as fases de cicatrização de } \\
\text { feridas, ao mesmo tempo em que estimula anexos } \\
\text { cutâneos abundantes e promover cura rápida, } \\
\text { representado o tratamento mais atraente }\end{array}$ \\
\hline 10 & $\begin{array}{l}\text { Avaliação in vitro do ácido } \\
\text { hialurônico/ alginato pó } \\
\text { composto para hemostasia } \\
\text { tópica e ferida } \\
\text { curando }\end{array}$ & 2020 & $\begin{array}{l}\text { Yi-Wen Chen, Chia- } \\
\text { Hsin Lu, Meng-Han } \\
\text { Shen, Shih-Yeh Lin, } \\
\text { Chia-Hui Chen, } \\
\text { Ching-Kuang } \\
\text { Chuang, Chia-Che Ho }\end{array}$ & $\begin{array}{l}\text { Os resultados indicaram que o RapidClot revelou } \\
\text { melhor capacidade de adsorção de água e menor } \\
\text { tempo de coagulação do sangue (132,7 segundos) do } \\
\text { que dois agentes hemostáticos disponíveis } \\
\text { comercialmente Celox (378,7 segundos) e } \\
\text { WoundSeal (705,3 segundos) }\end{array}$ \\
\hline
\end{tabular}


Fonte: Pesquisa direta em bases de dados. Teresina (2021).

\section{Discussão}

Com base nos achados da literatura, foi observável que o ácido hialurônico configura uma importante ferramenta no tratamento de pacientes com pé diabético, com eficácia comprovada basicamente em todos os estudos, o ácido ainda possui um custo baixo e acessível, fornecendo assim uma facilidade para os pacientes que necessitam de tratamento. No entanto apesar dos vastos benefícios e vantagens que o ácido hialurônico fornece, foi constatado poucos estudos relacionados a esta temática.

Nos estudos de Wang, Han, Guo \& Huang (2016) em que foram utilizados ratos diabéticos para avaliar a eficácia na promoção da cicatrização de feridas com ácido hialurônico, foi possível observar que a aplicação tópica da pomada contendo $0,15 \%$ deste ácido foi eficaz na redução do tamanho da ferida dos ratos selecionados no estudo, e também foi constatado em 14 dias pós-ferimento o ácido aumentou a granulação do tecido e revitalização da ferida; nesse mesmo estudo detectou que o HA melhorou o suprimento de sangue para área da ferida. No entanto se comparados aos resultados dos estudos de Hsu, Liu, Yeh, Lin, Wu \& Tsai (2019) que também foi utilizado camundongos diabéticos para avaliar os efeitos do ácido hialurônico o fechamento das feridas ocorreram em um período de tempo menor que o citado anteriormente, advindo no decorrer de 10 dias após o ferimento, o mesmo também manifestou boa capacidade para absorção água sendo que a utilização do hidrogel uma vez a cada 3 dias melhorou drasticamente na cicatrização da ferida em comparação ao grupo que foi tratado com o mesmo hidrogel uma vez ao dia.

É notável que o ácido hialurônico se mostrou consideravelmente eficaz não só em estudos envolvendo ratos, mas também em coelhos e seus resultados se assemelham em relação ao período de cicatrização, nos estudos de Honda et al. (2017) a utilização do HA empregados em coelhos para avaliar os efeitos do mesmo, foi notável uma rapidez na cicatrização do tendão ao osso em um modelo de ruptura do manguito rotador, confirmando assim que o ácido hialurônico acelera a condrogênese por (MSCs) in vitro e aumenta a força biomecânica com crescimento no tecido condroide do modelo animal, dados esses que se assemelham aos dados de Iacopetti, Perazzi, Martinello, Gemignani \& Patruno (2020), pois além da aceleração do processo de cicatrização, também foi visto na primeira semana o volume do exsudato que se apresentava serossanguíneo diminuiu gradativamente, assim como o tecido de granulação relacionado a uma tendencia fisiológica que em 42 dias após o ferimento, ocorreu a reepitelização completa do tecido, favorecendo assim a cura do mesmo.

De acordo com Silva et al. (2017) na avaliação da cura de feridas diabéticas de camundongos diabéticos usando hidrogeis esponjosos à base de ácido hialurônico carregados com células-tronco, foi notado que após a 2 semanas do tratamento, houve uma considerável camada fina de queratinócitos migrando em direção à ferida, do qual a presença destas células agem promovendo a síntese de queratina, facilitando assim a cicatrização, e promovendo aspectos positivos quanto a epitelização e pela modulação da resposta inflamatória em busca da cura. Assim como demonstrados nos estudos de Lee et al. (2016), como também em outras pesquisas, os curativos realizados com ácido hialurônico apresentou resultados favoráveis com relação a rapidez da cicatrização e taxa de cura completa.

Segundo Park, Park \& Yi (2017) o emprego da injeção de ácido hialurônico com antibióticos para prevenção e tratamento de infecção de sítio cirúrgico causados por Staphylococcus aureus, o grupo que foi exposto ao HA notou-se uma menor quantidade de secreção, menos purulência e odor fétido, também foi observado uma considerável diminuição da área da ferida e a contagem bacteriana no quarto dia foi menor; resultados esses que também se revelam em Gazzabin, Serantoni, Palumbo \& Giordan (2019) em que após um dia de aplicação do pó de spray tópico contendo ácido hialurônico (HÁ) e metal de prata houve redução na área da ferida, assim como foi perceptível a diminuição de alguns sinais clínicos como odor, nível de exsudato que no decorrer do tratamento otimizou complacente, além do desaparecimento completo de eritema de pele periférica que era evidente em todas as feridas que foram selecionadas no estudo. 
Nos estudos de Marin, Popović-Pejičić, Radošević-Carić, Trtić, Tatić \& Selaković (2020) e Chen et al. (2020) foi evidenciado que a aplicação do ácido hialurônico revelou melhor capacidade de absorção de água, mantendo a rigidez como um antimicrobial de barreira nos primeiros dias de aplicação, deduzindo assim que 0,8\% do ácido colocado nos alvéolos pós extração em pacientes diabéticos melhora significativa a cicatrização da ferida, especialmente nos primeiros dias de aplicação, no segundo estudo ainda foi visto um menor tempo de coagulação comparada a outros agentes hemostáticos, e degradação enzimática comparável a capacidade e citocompatibilidade contra NIH /3 T3 fibroblastos, bem como a taxa de proliferação celular foi superior a outros agentes abordados no estudo. É notável que os efeitos do ácido hialurônico não só em pacientes com pé diabético, como também por outras complicações relacionadas a sua condição tem resultados benéficos e favoráveis em curto período de tempo após início do tratamento.

\section{Considerações finais}

No presente estudo, foi possível concluir que o ácido hialurônico configura uma importante ferramenta para o tratamento de feridas do pé diabético e sobretudo em diversas partes do corpo. O ácido se mostrou bastante eficaz na maioria dos estudos selecionados, não demonstrando contraindicações severas e nem efeitos maléficos que condissessem repercussões negativas ao seu uso.

Os principais efeitos observados na utilização deste ácido, isoladamente ou combinado com outras substancias foram: rapidez na cicatrização de feridas reduzindo seu tamanho em um curto período de tempo, aumento da granulação do tecido e revitalização da ferida, melhora no suprimento de sangue até o local da ferida, produção de queratinócitos, redução de alguns sinais clínicos como: secreção, purulência, odor e nível de exsudato; desaparecimento de eritema de pele periférica, demonstrando boa capacidade de absorção de água com taxa de cura completa.

Assim como observado em outros acervos, o emprego do ácido hialurônico utilizado de forma isolada, demonstrou eficácia na melhora da dor em comparação com outras terapias num estudo que se investigava os efeitos desse ácido para diagnósticos de deslocamento de disco e osteoartrites da ATM (Ferreira, 2018 como citado em Santos, 2020, p. 9).

O estudo evidenciou um limitado número de acervos relacionados a temática abordada, fomentado a importância de se realizar novos estudos sobre os efeitos do ácido hialurônico no tratamento do pé diabético, sobretudo a ação que este promove para diminuir as altas taxas de amputação de membros inferiores, ocasionados pelo tratamento feito de forma incorreta ou com substancias que não contém os mesmos efeitos do ácido do estudado ou mesmo pela ausência de tratamento. Nesse sentido, objetiva-se contribuir para pesquisa científica, favorecendo na assistência que é prestada pelos profissionais da saúde, visando os obstáculos que os mesmos encontram diariamente diante dos desafios de se realizar cuidados ao pé diabético, reconhecendo a relevância do tema desenvolvido e os impactos que o mesmo ocasiona.

Sendo assim, o presente estudo sugere a criação de novos estudos sobre os efeitos do ácido hialurônico no tratamento do pé diabético, suscitando o preparo de profissionais para desempenhar um tratamento com mínimo de complicações, visando sobretudo a cura nesses grupos.

\section{Referências}

Bernardo, A. F. C., Santos, K., \& Silva, D. P. (2019). Pele: alterações anatômicas e fisiológicas do nascimento à maturidade. Revista Saúde em Foco, 1(11), 1221-33. Recuperado de http://portal.unisepe.com.br/unifia/wpcontent/uploads/sites/10001/2019/11/PELEALTERA\%C3\%87\%C3\%95ESANAT\%C3\%94MICAS-E-FISIOL\%C3\%93GICAS-DONASCIMENTO-\%C3\%80-MATURIDADE.pdf

Chen, Y. W., Lu, C. H., Shen, M. H., Lin, S. Y., Chen, C. H., Chuang, C. K., \& Ho, C. C. (2020). In vitro evaluation of the hyaluronic acid/alginate composite powder for topical haemostasis and wound healing. International wound journal, 17(2), 394-404. DOI: 10.1111/iwj.13285

Dalmedico, M. M., Meier, M. J., Felix, J. V. C., Pott, F. S., Petz, F. D. F. C., \& Santos, M. C. (2016). Coberturas de ácido hialurónico en el tratamiento de quemaduras: revisión sistemática. Revista da Escola de Enfermagem da USP, 50(3), 522-528. DOI: http://dx.doi.org/10.1590/S0080-623420160000400020 
da Silva, L. P., Santos, T. C., Rodrigues, D. B., Pirraco, R. P., \& Cerqueira, M. T. (2017). Stem cell-laden hyaluronic acid-based spongy-like hydrogels for an integrated healing of diabetic wounds pathophysiologies. J. Investig. Dermatol, 137, 1541-51. DOI: 10.1016/ j.jid.2017.02.976

de Pádua, A. K. R. (2020). Estudo de caso: ação do ácido hialurônico e ativos naturais na cicatrização de feridas-Pharmacure®. Saúde Coletiva (Barueri), 10(55), 3013-3022. DOI: https://doi.org/10.36489/saudecoletiva.2020v10i55p3013-3022

Ferreira, R. C. (2020). Pé diabético. Parte 1: Úlceras e Infecções. Revista Brasileira de Ortopedia, 55(4), 389-396. DOI: https://doi.org/10.1055/s-00393402462

de Gois, J. P. D. S., \& Chaves, A. S. C. (2020). Pé diabético: avaliação dos fatores de risco relacionados a amputações maiores e menores. Revista Eletrônica Acervo Saúde, 12(1), e1484-e1484. DOI: https://doi.org/10.25248/reas.e1484.20

De Sousa, L. M. M., Firmino, C. F., Marques-Vieira, C. M. A., Severino, S. S. P., \& Pestana, H. C. F. C. (2018). Revisões da literatura científica: tipos, métodos e aplicações em enfermagem. Revista Portuguesa de Enfermagem de Reabilitação, 1(1), 45-54. Recuperado de http://hdl.handle.net/10174/25938

Ercole, F. F., Melo, L. S. D., \& Alcoforado, C. L. G. C. (2014). Revisão integrativa versus revisão sistemática. Revista Mineira de Enfermagem, 18(1), 9-12. DOI: http://www.dx.doi.org/10.5935/1415-2762.20140001

Gazzabin, L., Serantoni, S., Palumbo, F. P., \& Giordan, N. (2019). Hyaluronic acid and metallic silver treatment of chronic wounds: healing rate and bacterial load control. Journal of wound care, 28(7), 482-490. DOI: 10.12968 / jowc.2019.28.7.482

Honda, H., Gotoh, M., Kanazawa, T., Ohzono, H., Nakamura, H., Ohta, K., ... \& Shiba, N. (2017). Hyaluronic acid accelerates tendon-to-bone healing after rotator cuff repair. The American journal of sports medicine, 45(14), 3322-3330. DOI: https://doi.org/10.1177/0363546517720199

Hsu, Y. Y., Liu, K. L., Yeh, H. H., Lin, H. R., Wu, H. L., \& Tsai, J. C. (2019). Sustained release of recombinant thrombomodulin from cross-linked gelatin/hyaluronic acid hydrogels potentiate wound healing in diabetic mice. European Journal of Pharmaceutics and Biopharmaceutics, 135, 61-71. DOI: https://doi.org/10.1016/j.ejpb.2018.12.007

Iacopetti, I., Perazzi, A., Martinello, T., Gemignani, F., \& Patruno, M. (2020). Hyaluronic acid, Manuka honey and Acemannan gel: wound-specific applications for skin lesions. Research in veterinary science, 129, 82-89. DOI: https://doi.org/10.1016/j.rvsc.2020.01.009

Laureano, A., \& Rodrigues, A. M. (2011). Cicatrização de feridas. Journal of the Portuguese Society of Dermatology and Venereology, 69(3), 355-367. DOI: https://doi.org/10.29021/spdv.69.3.71

Lee, M., Han, S. H., Choi, W. J., Chung, K. H., \& Lee, J. W. (2016). Hyaluronic acid dressing (Healoderm) in the treatment of diabetic foot ulcer: a prospective, randomized, placebo-controlled, single-center study. Wound Repair and Regeneration, 24(3), 581-588. DOI: 10.1111 / wrr.12428

Marin, S., Popović-Pejičić, S., Radošević-Carić, B., Trtić, N., Tatić, Z., \& Selaković, S. (2020). Hyaluronic acid treatment outcome on the post-extraction wound healing in patients with poorly controlled type 2 diabetes: A randomized controlled split-mouth study. Medicina oral, patologia oral y cirugia bucal, 25(2), e154. DOI: https://dx.doi.org/doi:10.4317/medoral.23061

Mendes, K. D. S., Silveira, R. C. D. C. P., \& Galvão, C. M. (2008). Revisão integrativa: método de pesquisa para a incorporação de evidências na saúde e na enfermagem. Texto \& contexto-enfermagem, 17(4), 758-764. DOI: https://doi.org/10.1590/S0104-07072008000400018

Oliveira, M. H. H. P. D., de-Sousa, M. S. C., Fernandes, N. M. S., Basílio, E. E. F., De Menezes, A. B., De Souza, M. A. B., \& Castilho, J. C. (2017). Uso do ácido hialurônico e da película de biocelulose no tratamento tópico de queimadura. Revista Brasileira de Queimaduras, 16(2), 135-138. Recuperado de http://www.rbqueimaduras.com.br/details/375/pt-BR/uso-do-acido-hialuronico-e-da-pelicula-de-biocelulose-no-tratamento-topico-de-queimadura

Park, J. H., Park, E. J., \& Yi, H. S. (2017). Wound healing and anti-inflammatory effects of topical hyaluronic acid injection in surgical-site infection caused by Staphylococcus aureus. The international journal of lower extremity wounds, 16(3), 202-207. DOI: 10.1177 / 1534734617714142

Soares, C. B., Hoga, L. A. K., Peduzzi, M., Sangaleti, C., Yonekura, T., \& Silva, D. R. A. D. (2014). Revisão integrativa: conceitos e métodos utilizados na enfermagem. Revista da Escola de Enfermagem da USP, 48(2), 335-345. DOI: https://doi.org/10.1590/S0080-6234201400002000020

Wang, Y., Han, G., Guo, B., \& Huang, J. (2016). Hyaluronan oligosaccharides promote diabetic wound healing by increasing angiogenesis. Pharmacological Reports, 68(6), 1126-1132. DOI: http://dx.doi.org/doi:10.1016/j.pharep.2016.07.001 